\title{
Evolving Paradigms in HIV Malignancies: Review of Ongoing Clinical Trials
}

\author{
Rachel A. Bender Ignacio, MD, MPH ${ }^{\mathrm{a}, \mathrm{b}}$; Lilie L. Lin, MDc; Lakshmi Rajdev, MD; \\ and Elizabeth Chiao, MD, MPH ${ }^{\mathrm{e}, \mathrm{f}}$
}

\begin{abstract}
This review highlights current interventional clinical trials for HIV-associated malignancies (HIVAMs), with emphasis on 4 mechanistic areas: immunomodulatory therapies and gene therapies, including immune checkpoint inhibitors; cytotoxic therapies; novel tumor-targeted and virally targeted therapies in both AIDS-defining and non-AIDS-defining cancers (NADC); and other screening or topical/ablative interventions. A search on ClinicalTrials.gov located 35 trials, including 12 immunomodulatory or gene therapy trials, 6 cytotoxic therapy trials, 10 trials of therapies with tumor or viral molecular targets, and 7 trials evaluating screening interventions or topical or ablative therapies. Study drugs, mechanisms, and outcomes of interest, including future directions, are discussed. Targeted therapies and immunotherapies address not only the tumor but underlying viral oncogens, including possible benefits on HIV-specific immunologic control. The resulting science from the trials listed in this review will provide important translational breakthroughs for people living with HIV (PLWH) and cancer. We highlight disease-specific challenges that could be addressed in future studies, including testing the safety and efficacy of cuttingedge immunotherapy and targeted treatments used in the general cancer population, and improving gaps in knowledge and practice for cancer screening and its treatment, especially in low-resource regions. Additional important considerations include identification of novel therapies for virally mediated tumors that disproportionally present in PLWH, how to treat persons with HIVAM and advanced immunosuppression, and how to comanage both diseases in antiretroviral therapy-naïve persons and those receiving care in settings where supportive therapies for hematologic toxicities and infections are limited. Current and future clinical trials should address needs of both resourcereplete and-limited regions, as well as cancers that are uncommon in or respond differently to HIV-negative populations (eg, Kaposi sarcoma or anal cancer), in addition to an increased focus on NADCs not traditionally linked with HIV, such as lung or gastrointestinal tumors.
\end{abstract}

Since the advent of combination antiretroviral therapy (ART), malignancies have become among the leading causes of death in persons living with HIV (PLWH). ${ }^{1}$ As treatment outcomes for PLWH and malignancies have improved in the past 2 decades, clinical trials for HIV-associated malignancies (HIVAMs) have also tremendously evolved. Until recently, most cancerspecific treatment trials excluded PLWH. For example, the Friends of Cancer Research HIV Working Group reviewed eligibility criteria from studies supporting 46 new drug applications of agents in patients with cancer

a University of Washington, and ' $F$ red Hutchinson Cancer Research Center, Seattle, Washington; 'The University of Texas MD Anderson Cancer Center Houston, Texas; ${ }^{d}$ Montefiore Medical Center, New York, New York; and

eBaylor College School of Medicine, and ${ }^{\mathrm{f}}$ DeBakey Veterans Affairs Medical

Center, Houston, Texas.

Submitted May 30, 2018; accepted for publication July 23, 2018.

Dr. Lin has disclosed that she has received grant/research support from AstraZeneca. The remaining authors have disclosed that they

have no financial interests, arrangements, affiliations, or commercial that led to FDA approval from 2011 to 2015 and found that $74 \%$ of these studies had HIV-specific or general infection exclusion criteria, likely excluding PLWH. However, they also reported on 13 studies that specifically included PLWH, and from these studies summarized several potential approaches for including PLWH in future cancer trials. They concluded that although HIV infection should no longer be an exclusion criterion for most cancer trials, concurrent ART therapy and immune status should be considered in the development of trial eligibility criteria. ${ }^{2}$

interests with the manufacturers of any products discussed in this article or their competitors.

Research reported in this publication was supported by $\mathrm{NCl}$ of the National Institutes of Health (U01CA121947 and R01CA206476) and by NIAID of the NIH (K23AI129659).

Correspondence: Rachel A. Bender Ignacio, MD, MPH, Fred Hutchinson Cancer Research Center, 1100 Fairview Avenue N, E2-112, Seattle, WA 98109. Email: rbi13@uw.edu; and

Elizabeth Chiao, MD, MPH, DeBakey Veteran's Affairs Medical Center, 2002 Holcombe Boulevard, Houston, TX 77030. Email: echiao@bcm.edu 
Study of ART use with HIVAM treatment is particularly important, because the WHO only recently began to strongly recommend initiating ART for all PLWH regardless of CD4-positive T-cell count (CD4 count) after 2 large randomized trials demonstrated overall benefit, especially in terms of non-AIDS-defining morbidity and mortality. ${ }^{3-5}$ Further understanding of the role of chronic immune activation and exhaustion in both HIV and cancer has also supported the idea that ART and cancer-directed therapies must go hand-in-hand. ${ }^{6-9}$ Thus, in cancers common in non-HIV-infected populations, many trials have had to focus on safety and pharmacokinetic studies in persons on ART, simply to prove that the regimen can be tolerated immunologically and that these regimens do not cause drug-drug interactions with strong inducers or inhibitors of cytochrome P450 enzymes (eg, efavirenz or protease inhibitors, respectively).

In addition, the burden of cancer is now being seen in sub-Saharan Africa (SSA) and other resource-limited regions, where longer life expectancy on ART and higher burden of viral oncogens has caused HIVAMs to become the second-leading cause of death, after tuberculosis, in PLWH. Thus, current and future clinical trials will need to address the needs of both resource-replete and resource-limited areas, as well as cancers that are uncommon or respond differently in HIV-negative populations, such as Kaposi sarcoma (KS) or anal cancer. This review summarizes and highlights current HIVAM clinical trials, with emphasis on 4 mechanistic areas: immunomodulatory therapies and gene therapies, including immune checkpoint inhibitors (ICIs); cytotoxic therapies; novel tumor-targeted and virally targeted therapies in both AIDS-defining cancers (eg, KS, AIDS-defining lymphomas, and cervical cancer) and non-AIDS-defining cancers (NADCs); and other screening or topical/ablative interventions.

\section{Process}

We initiated a search on ClinicalTrials.gov using the following search terms: "HIV" or "AIDS" or "acquired immunodeficiency syndrome" plus "malignancy," "cancer," "squamous intraepithelial lesions," or "Kaposi sarcoma." We limited trials to interventional treatment and screening trials, and included only those listed as active, recruiting, enrolling, or not yet recruiting. A total of 35 trials were found, including 12 immunomodulatory or gene therapy trials, 6 cytotoxic therapy trials, 10 trials of therapies with tumor or viral molecular targets, and 7 trials evaluating screening interventions or topical or ablative therapies.

\section{ICls, Gene Therapy, and Other Immunotherapies}

Among the immunomodulatory or gene therapy trials, most were phase I or I/II ( $n=9$; Table 1$)$. Most of the trials focused on lymphoma $(n=6), 2$ on $K S, 1$ on non-small cell lung cancer, 1 on multiple tumor types, and 1 on human papillomavirus (HPV)-related cancers. There were only 3 phase II studies, all of which involved a PD-1 inhibitor alone or in combination with a CTLA-4 inhibitor. In addition, 5 of the lymphoma studies evaluated gene-modified stem cell trials with or without cytotoxic chemotherapy, with 1 phase I/II allogeneic Epstein-Barr virus (EBV)-specific cytotoxic T-cell transplant trial for EBV-associated lymphoproliferative disorders. Lastly, there were 2 studies of pomalidomide, a thalidomide analog and immunomodulatory drug (IMiD) that augments $\mathrm{T}$ cell- and NK-cell-mediated immunity and exerts antiangiogenic and antineoplastic effects. ${ }^{10}$ These trials evaluated pomalidomide in combination with liposomal doxorubicin for advanced or refractory $\mathrm{KS}$, and pomalidomide alone in individuals with high-grade squamous intraepithelial lesions (HSIL).

\section{Immunomodulatory Agents and Effects on HIV-1 Replication and Latency}

Blocking of both PD-1 and CTLA-4 in HIV-1-specific, CD4- and CD8-positive T cells leads to a recovery of cell proliferation and cytokine production in vitro. ${ }^{11}$ Furthermore, CTLA-4 blockade also increases CD4-positive T-cell proliferation and augments HIV-specific CD4-positive T-cell function. ${ }^{12,13}$ In a simian immunodeficiency virus (SIV)-infected macaque model, blockade of PD-1 by a monoclonal antibody increased the number of virus-specific CD4-positive T cells and memory B cells and levels of envelope-specific antibodies. These immunologic effects were associated with the lack of side effects and significantly increased overall survival of the treated SIV-infected macaques. ${ }^{14}$

Given these promising data, several ICI trials, including the AMC-095 study of combined CLTA4/PD-1 blockade, featured laboratory end points, in- 
Bender Ignacio et al

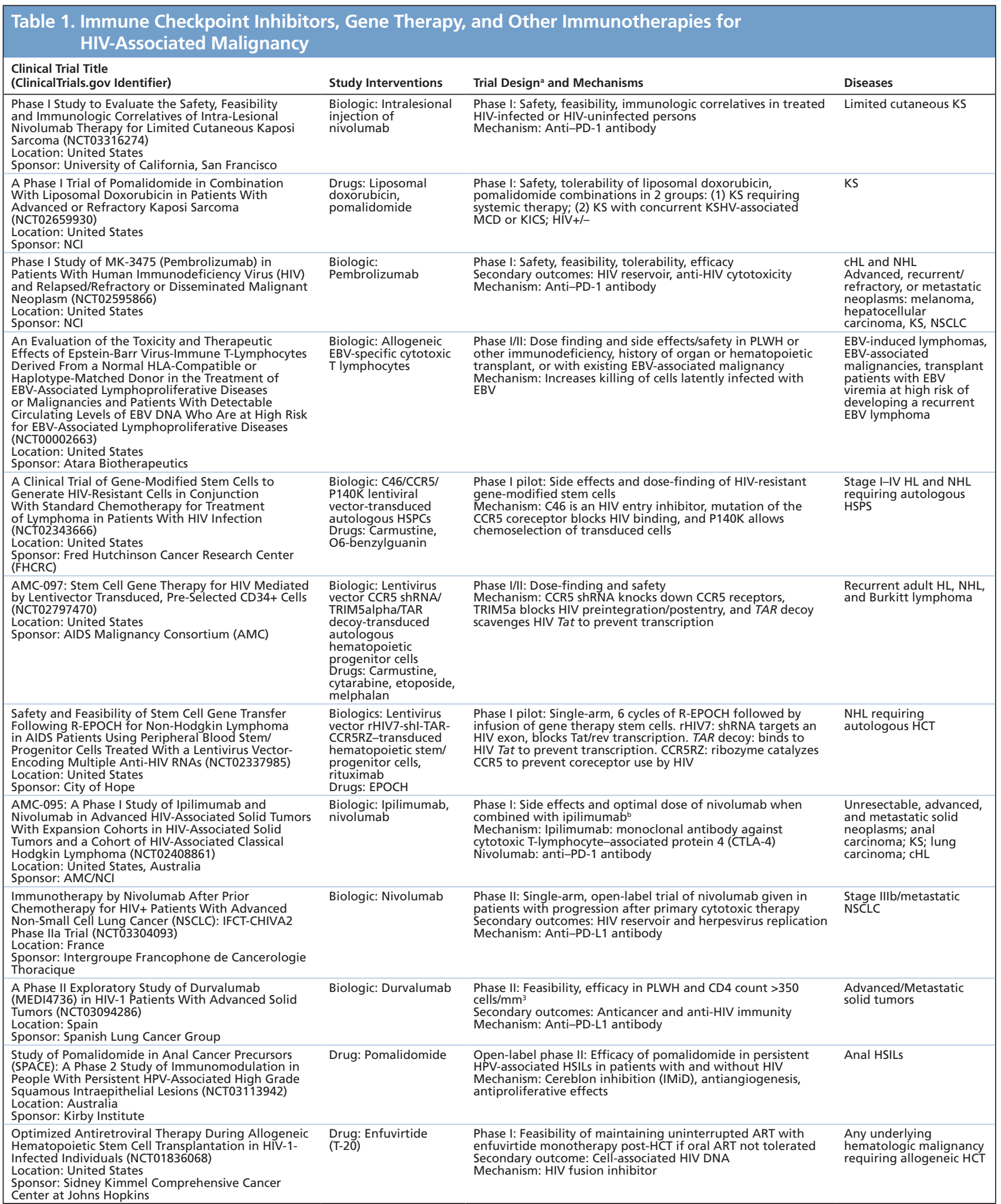

Abbreviations: ART, antiretroviral therapy; CHL, classic Hodgkin lymphoma; EBV, Epstein-Barr virus; EPOCH, etoposide/prednisone/vincristine/cyclophosphamide/doxorubicin; $\mathrm{HCT}$, hematopoietic cell transplant; HL, Hodgkin lymphoma; HPV, human papillomavirus; HSIL, high-grade squamous intraepithelial lesion; HSPS, hematopoietic stem and progenitor cell; IMiD, immunomodulatory drug; KICS, Kaposi sarcoma-associated herpesvirus inflammatory cytokine syndrome; KS, Kaposi sarcoma; KSHV, Kaposi sarcomaassociated herpesvirus; MCD, multicentric Castleman disease; NHL, non-Hodgkin's lymphoma; NSCLC, non-small cell lung cancer; PLWH, persons living with HIV; shRNA, short hairpin RNA.

aUnless otherwise noted, trials include only persons with treated HIV infection (ie, on ART and/or virologic control). Noted studies include persons without HIV infection.

bUntreated HIV allowed as long as the participant is either stable while on or not on ART for 4 weeks before and then during the study. 
cluding quantitation of the replication-competent viral reservoir in peripheral blood mononuclear cells, and measurement of anti-HIV-specific $\mathrm{T}$ cells. The French ANRS CO24 OncoVIHAC cohort will prospectively follow all available PLWH who receive ICIs as part of routine cancer care to evaluate their safety and effects on the HIV reservoir (ClinicalTrials.gov identifier: NCT03354936). The Cancer Immunotherapy Trials Network (CITN) trial of pembrolizumab in solid tumors and Hodgkin lymphoma will also address these questions through longitudinal analysis of the replication-competent HIV reservoir (ClinicalTrials.gov identifier: NCT02595866).

\section{Hematopoietic Cell Transplant and Gene Therapy Trials}

Current allogeneic and autologous hematopoietic cell transplant (HCT) trials focus on safely increasing the aggressiveness of conditioning regimens, as well as leveraging clinical indications for autologous HCT to investigate gene therapies for functional HIV cure. City of Hope is currently testing the safety and impact of high-dose conditioning with carmustine, etoposide, and cyclophosphamide followed by autologous HCT on HIV-specific immune reconstitution in patients with HIV-associated lymphoma (NCT02337985). Preliminary results of the CTN 0903/AMC-080 trial showed that overall survival in myeloablative/nonablative transplant recipients with HIV was similar to historical results for nonHIV-infected persons ( $82 \%$ at 6 months, $57 \%$ at 1 year), with no deaths attributable to HIV..$^{15}$ Another ongoing study is evaluating the feasibility and efficacy of subcutaneous enfuvirtide monotherapy as a bridge for patients who are unable to take oral ART following HCT (ClinicalTrials.gov identifier: NCT01836068).

Several active trials leverage clinically indicated HCT to test gene-edited autologous hematopoietic cells targeted at HIV. Each study is using a lentivirus vector with 3 gene targets in different combinations. AMC-097 is evaluating transduced autologous CD34positive cells with short hairpin RNA (shRNA) CCR5 that causes interference to transcription of this gene, preventing expression of one crucial coreceptor required for HIV-1 cell entry. TRIM5 $\alpha$ prevents proviral integration by blocking uncoating of HIV capsids in the cytosol, which is thought to be one of the factors that render rhesus monkeys resistant to HIV infection.
The last component is a TAR decoy oligonucleotide, which outcompetes HIV Tat to prevent transcription at the promoter. ${ }^{16}$ The study from Fred Hutchinson Cancer Research Center (NCT02343666; Table 1) pairs a mutated CCR5 sequence with an HIV entry inhibitor (C46) and a chemoselection agent (P140K). P140K causes cellular resistance to O6-benzylguanine, a highly toxic suicide inhibitor, thus enriching the population of transduced cells while depressing both nontransformed HCT and malignant cell lines. The last study tests a rHIV7-shI-TAR-CCR5RZ combination, again targeting TAR and CCR5, this time through a ribozyme that catalyzes CCR5, added to a different shRNA (rHIV7), which blocks transcription of HIV Tat/Rev (NCT02337985).

\section{Cytotoxic Chemotherapy}

Of the 6 trials evaluating novel cytotoxic therapeutic trials, 5 are accruing PLWH with Hodgkin's or nonHodgkin lymphomas (Table 2). Early findings from the only phase I/II safety and efficacy trial evaluating substitution of the CD30 monoclonal antibody brentuximab vedotin for bleomycin has demonstrated safety in 7 patients. ${ }^{17}$ Other studies evaluating cytotoxic therapy are phase II studies determining the safety and efficacy of other novel therapies for HIV-associated lymphoma, including short-course EPOCH (etoposide/prednisone/vincristine/cyclophosphamide/doxorubicin) and the addition of ibrutinib in dose-adjusted EPOCH as frontline treatment (NCT00006436 and NCT03220022, respectively). One trial is evaluating the safety and efficacy of rituximab plus CHOP (prednisone/vincristine/cyclophosphamide/ doxorubicin) in Malawi, a resource-limited setting (NCT02660710), and another is determining the efficacy of methotrexate/leucovorin/rituximab in primary central nervous system lymphoma (NCT00267865). The only currently open phase III trial in this group is evaluating the novel modulated electrohyperthermia (mEHT; Oncothermia) plus standard chemoradiotherapy for locally advanced cervical cancer in South Africa (NCT03332069). Previous studies have shown that the addition of hyperthermia to conventional cytotoxic therapy improves treatment efficacy. ${ }^{18} \mathrm{mEHT}$ utilizes the principles of extracellular hyperthermia using low frequency modulated direct electroic field, but not temperature-dependent, effects of electromagnetic fields and special modulation, the effect of 
Bender Ignacio et al

\begin{tabular}{|c|c|c|c|}
\hline $\begin{array}{l}\text { Clinical Trial Title } \\
\text { (ClinicalTrials.gov Identifier) }\end{array}$ & Study Interventions & Trial Design ${ }^{\mathrm{a}}$ and Mechanisms & Diseases \\
\hline $\begin{array}{l}\text { A Pilot Trial of AVD and Brentuximab Vedotin } \\
\text { (SGN-35) in the Treatment of Stage II-IV HIV- } \\
\text { Associated Hodgkin Lymphoma (NCT01771107) } \\
\text { Location: United States, France } \\
\text { Sponsor: NCl }\end{array}$ & $\begin{array}{l}\text { Drugs: Brentuximab vedotin } \\
\text { + dacarbazine, doxorubicin } \\
\text { hydrochloride, vinblastine }\end{array}$ & $\begin{array}{l}\text { Pilot phase I/II: Dose finding, side effects, efficacy } \\
\text { Mechanism: Chimeric monoclonal antibody } \\
\text { to CD } 30 \text { conjugated to the antimitotic agent } \\
\text { monomethyl auristatin } E \text { (MMAE or vedotin) }\end{array}$ & $\begin{array}{l}\text { AIDS-related stage } \\
\text { II-IV HL }\end{array}$ \\
\hline $\begin{array}{l}\text { Short-Course EPOCH-Rituximab in Untreated CD- } \\
\text { 20+ HIV-Associated Lymphoma (NCT00006436) } \\
\text { Location: United States } \\
\text { Sponsor: NCl }\end{array}$ & $\begin{array}{l}\text { Biologics: Rituximab, filgrastim } \\
\text { Drugs: EPOCH }\end{array}$ & $\begin{array}{l}\text { Nonrandomized phase II: Dose-descalation study; } \\
\text { treatment every } 3 \text { weeks with combination of } \\
\text { EPOCH + rituximab for } 1 \text { cycle beyond complete } \\
\text { response by CT of all detectable tumors for a } \\
\text { minimum of } 3 \text { and maximum of } 6 \text { cycles }\end{array}$ & $\begin{array}{l}\text { AIDS-related NHL, } \\
\text { DLBCL }\end{array}$ \\
\hline $\begin{array}{l}\text { LCCC 1335: A Single-Arm Phase I/II Clinical Trial of } \\
\text { Rituximab Plus CHOP Chemotherapy for Diffuse } \\
\text { Large B-cell Lymphoma in Malawi (NCT02660710) } \\
\text { Location: Malawi } \\
\text { Sponsor: UNC Lineberger Comprehensive Cancer } \\
\text { Center }\end{array}$ & $\begin{array}{l}\text { Biologic: Rituximab } \\
\text { Drugs: Cyclophosphamide, } \\
\text { doxorubicin hydrochloride, vincristine } \\
\text { sulfate, prednisone (R-CHOP) }\end{array}$ & $\begin{array}{l}\text { Nonrandomized phase II: } 40 \text { adult patients aged } \\
18-60 \text { years ( } 20 \text { HIV-infected with CD4 count } \\
\geq 100 \text { cells } / \mathrm{mm}^{3}, 20 \text { HIV-uninfected) will receive a } \\
\text { maximum of } 6-8 \text { cycles of R-CHOP } \\
\text { Outcome: To establish the safety of R-CHOP in the } \\
\text { Malawi population }\end{array}$ & DLBCL, HIV \\
\hline $\begin{array}{l}\text { Phase I and Dose-Expansion Study of Ibrutinib and } \\
\text { R-da-EPOCH for Front Line Treatment of AIDS- } \\
\text { Related Lymphomas (NCT03220022) } \\
\text { Location: United States } \\
\text { Sponsor: NCI }\end{array}$ & $\begin{array}{l}\text { Drugs: Cyclophosphamide, } \\
\text { doxorubicin hydrochloride, vincristine } \\
\text { sulfate, etoposide, prednisone, } \\
\text { ibrutinib } \\
\text { Biologic: Rituximab }\end{array}$ & $\begin{array}{l}\text { Phase I: Side effects, dose finding of ibrutinib in } \\
\text { combination with R-EPOCH in stage II-IV DLBCLs }\end{array}$ & AIDS-related NHL \\
\hline $\begin{array}{l}\text { Chemotherapy and HAART to Treat AIDS-related } \\
\text { Primary Brain Lymphoma (NCT00267865) } \\
\text { Location: United States } \\
\text { Sponsor: NCI }\end{array}$ & $\begin{array}{l}\text { Drugs: Methotrexate, leucovorin } \\
\text { Biologic: Rituximab }\end{array}$ & $\begin{array}{l}\text { Nonrandomized phase II: Induction with } \\
\text { rituximab, high-dose methotrexate, leucovorin } \\
\text { every } 2 \text { weeks } x 6 \text { cycles. Consolidation with high- } \\
\text { dose methotrexate alone }\end{array}$ & $\begin{array}{l}\text { Primary central } \\
\text { nervous system } \\
\text { lymphomas }\end{array}$ \\
\hline $\begin{array}{l}\text { Modulated Electro-Hyperthermia Plus Chemo- } \\
\text { radiation for Locally Advanced Cervical Cancer } \\
\text { Patients in South Africa (NCT03332069) } \\
\text { Location: South Africa } \\
\text { Sponsor: National Research Foundation of South } \\
\text { Africa, NTP Radioisotopes SOC Ltd }\end{array}$ & $\begin{array}{l}\text { Device: } \mathrm{mEHT} \\
\text { Radiation: External-beam radiation, } \\
\text { brachytherapy } \\
\text { Drug: Cisplatin }\end{array}$ & $\begin{array}{l}\text { Phase III: Standard chemoradiotherapy with or } \\
\text { without mEHT for locally advanced cervical cancer. } \\
\text { End points: (1) local disease control at } 6 \text { months } \\
\text { on imaging, (2) progression-free survival }\end{array}$ & Cervical carcinoma \\
\hline
\end{tabular}

Abbreviations: AVD, doxorubicin/vincristine/dacarbazine; $\mathrm{CHOP}$, cyclophosphamide/doxorubicin/vincristine/prednisone; DLBCL, diffuse large B-cell lymphoma; EPOCH, etoposide/prednisone/vincristine/cyclophosphamide/doxorubicin; HL, Hodgkin lymphoma; mEHT, modulated electrohyperthermia; NHL, non-Hodgkin's lymphoma. aUnless otherwise noted, trials include only persons with treated HIV infection (ie, on ART and/or virologic control).

which may exceed that of the overall heating (macroscopic temperature elevation) by 3 - to 4 -fold. ${ }^{19} \mathrm{mEHT}$ does not require hyperthermia-range temperature and may be performed safely, without invasive thermal control. ${ }^{20}$

\section{Targeted and Molecular Therapies}

We identified 10 active trials of therapies targeted at viral oncogenes or other molecular targets, most of which are phase I or II (Table 3). Four trials include antiviral drugs for KS-associated herpesvirus (KSHV) activity in KS or KSHV-associated lymphoproliferative disorders. An NCI-sponsored study is evaluating 5 different oncolytic virotherapy approaches to multicentric Castleman's disease and/or KSHV-associated inflammatory cytokine syndrome (KICS), including combinations of zidovudine and ganciclovir, IMiDs, sirolimus, rituximab, and interferon- $\alpha$, with or without cytotoxic chemotherapy per underlying disease (NCT00092222). AMC-098 is studying nelfinavir, an early-generation HIV protease inhibitor once abandoned for its off-target effects, and more recently found to directly inhibit KSHV replication in vitro and in vivo (NCT03077451). ${ }^{21-23}$ This trial uses higher-than- standard nelfinavir dosing to parlay the well-known "off-target" effects on NFא, VEGF, HIF-1- $\alpha$, and PI3K/ Akt pathways. A Mexican government-sponsored study is evaluating the impact of 4 weeks of valganciclovir on KICS in ART- and treatment-naïve persons with limited KS (NCT03296553). Finally, a Brazilian study is evaluating the safety and maximum tolerated dose of using a class I histone deacetylase inhibitor (HDAC) "kick" followed by valganciclovir to "kill" latently infected KSHV-infected cells (NCT03397706).

Three additional KS trials target tumor angiogenesis. The first (AMC-096) uses recombinant soluble Ephrin B4 fusion protein (sEphB4-HSA) inhibition of the EphB2-VEGF pathway (NCT02799485). The second study is from the United Kingdom evaluating the safety and tolerability of selumetinib, an orally active, ATP-independent inhibitor of the mitogenactivated protein kinase kinase (MEK/ERK 1/2) pathway (NCT01752569). The third study (AMC087) is a multitumor phase I dose-finding study evaluating the safety of the c-MET/multi-tyrosine kinase inhibitor cabozantinib in PLWH, including patients with KS and several other cancers (NCT01822522).

Finally, 3 studies are evaluating antiviral approaches for HPV-related neoplasia. The first is an open-label 
HIV Malignancies: Ongoing Studies Review

\section{Table 3. Targeted and Molecular Therapies for HIV-Associated Malignancy}

\section{Clinical Trial Title (ClinicalTrials.gov Identifier) \\ AMC-098: A Pilot Study of Nelfinavir for the Treatment of Kaposi Sarcoma (NCT03077451) Location: United States and Uganda Sponsor: AMC \\ Valganciclovir for Suppression of HHV-8 Four Weeks Prior to Initiation of cART in Patients With Disseminated Kaposi Sarcoma Compare With Standard Therapy, Its Impact on the Development of IRIS and Attributable Mortality (NCT03296553) Location: Mexico \\ Sponsor: National Institute of Cancerología}

Targeted Oncolytic Virotherapy and Natural History Study of KSHV-Associated Multicentric Castleman's Disease With Laboratory and Clinical Correlates of Disease Activity (NCT00092222) Location: United States Sponsor: $\mathrm{NCl}$

AMC-096: sEphB4-HSA in Treating Patients With Kaposi Sarcoma (NCT02799485)

Location: United States

Sponsor: AMC

Study Interventions
Drug: Nelfinavir

Drugs: Valganciclovir + cART in

\section{Trial Design ${ }^{\mathrm{a}}$ and Mechanisms}

Phase II: Intra-person dose-escalation to high-dose nelfinavir. Efficacy against tumor and herpesvirus replication; HIV+ and HIV-study arms Mechanism: Antiviral protease inhibitor

Phase II: Randomized open-label: valganciclovir x 4 weeks followed by ART initiation with valganciclovir maintained until KSHV DNA undetectable in blood vs CART initiation alone in KS

Main outcome: Immune reconstitution inflammatory syndrome-related mortality Mechanism: Antiviral, DNA polymerase inhibition

Drugs: (1) High-dose zidovudine + ganciclovir

(2) High-dose zidovudine, ganciclovir + bortezomib

(3) Sirolimus

(4) Rituximab + liposomal

doxorubicin, interferon-alpha

(5) Rituximab + EPOCH

Biologic: Recombinant EphB4-HSA fusion protein

Phase II: Natural history, comparison of outcomes treatment in 1 of 5 parallel comparator arms depending on clinical course in HIV+/Main outcome: Evaluate natural history and clinical correlates of multicentric Castleman's disease treatments

Phase II: Efficacy and safety, evaluate effects on the (VEGF)-Notch-EphrinB2 angiogenic pathway in $\mathrm{HIV+/}$

Main outcome: Clinical response and toxicity of recombinant EphB4-HSA fusion protein (sEphB4HSA) (at initial dosing of $15 \mathrm{mg} / \mathrm{kg}$ every 2 weeks) Mechanism: Inhibition of EphA3 and EphB4 (antiangiogenesis)

A Study of Selumetinib in Patients With Kaposi's Drug: Selumetinib

Sarcoma (SCART) (NCT01752569)

Phase I: Completed, identified optimal dose.

Phase II: Safety and efficacy with ART

Mechanism: Mitogen-activated protein kinase

kinase (MEK/ERK 1/2)

Sponsor: Sheffield Teaching Hospitals NHS

Foundation Trust

A Phase 1b/2 Open-Label, Dose Escalation \& Expansion Study of Orally Administered VRx3996 \& Valganciclovir in Subjects With EpsteinBarr Virus-Associated Lymphoid Malignancies Barr Virus-Asso

(NCT03397706) Sponsor: Viracta Therapeutics, Inc.

AMC 087: Phase I Trial of Cabozantinib (XL184) for Advanced Solid Tumors in Persons With HIV Infection (NCT01822522)

Location: United States

Sponsor: $\mathrm{NCl}$

Open-Label Study to Evaluate the Safety, Tolerability, and Pharmacokinetics of Single and Multiple Doses of Topical ABI-1968 in Subjects With Anal High-Grade Squamous Intraepithelial Lesions (aHSIL) (NCT03202992)

Location: United States, Australia

Sponsor: Antiva Biosciences

AMC-099: A Randomized, Placebo-Controlled Trial of HPV Vaccination to Reduce Cervical High-Grade

Squamous Intraepithelial Lesions Among HIV-

Infected Women Participating in an HPV Test-and-

Treat Program (COVENANT) (NCT03284866)

Location: Kenya, Malawi, South Africa, Tanzania,

Uganda, Zimbabwe

Sponsor: AMC

HPV Vaccine to Interrupt Progression of Vulvar and Anal Neoplasia (VIVA) Trial: A Randomized, Double-Blind, Placebo-Controlled Trial (NCT03051516)

Location: United States

Sponsor: Fred Hutchinson Cancer Research Center

\section{Drugs: VRx-3996 (tractinostat),}

valganciclovir
Phase Ib/ll: Safety and maximally tolerated dose of VRx-3996 in combination with valganciclovir in $\mathrm{HIV+l}-$

Mechanism: Class I histone deacetylase inhibitor

"kick" with valganciclovir "kill" of latently EBV-infected cells

Drug: Cabozantinib S-malate

Phase I: To determine the safety and maximally tolerate dose of cabozantinib-s-malate ${ }^{\mathrm{b}}$ Mechanism: Multiple tyrosine kinase inhibitor of VEGFR-2, c-MET, RET

Drug: $A B I-1968$

Phase I: To evaluate topical ABI-1968, in treatment of anal precancerous lesions in $\mathrm{HIV}+$ /-

Mechanism: Acyclic nucleoside phosphate with

direct anti-HPV activity. Induces apoptosis only of HPV-infected cells

Biologic: Recombinant HPV nonvalent vaccine vs placebo

Phase III, randomized: Determine whether 9-valent vaccine prevents HSIL and cervical cancer in HIVpositive women on ART who have high-risk HPV but no lesions at baseline
Women with HIVIAIDS at risk

Diseases

Endemic, classic, and HIV-associated KS

KS

KSHV-associated lymphoproliferative disorders

KS KS

EBV-associated lymphoma Lymphoproliferative disorders

\section{Advanced/Recurrent/} Metastatic/ Unresectable solid neoplasms

Anal canal HSIL for cervical cancer

Abbreviations: ART, antiretroviral therapy; EBV, Epstein-Barr virus; EPOCH, etoposide/prednisone/vincristine/cyclophosphamide/doxorubicin; HPV, human papillomavirus; HSA, human serum albumin; HSIL, high-grade squamous intraepithelial lesion; KS, Kaposi sarcoma; KSHV, Kaposi sarcoma-associated herpesvirus.

anless otherwise noted, studies include only persons with treated HIV infection (ie, on ART and/or virologic control).

bUntreated HIV allowed as long as the participant is either stable while on or not on ART for 4 weeks before and then during the study.

phase I trial to determine the safety and tolerability of an acyclic nucleoside phosphate with direct anti-HPV activity for HSIL of the anal canal (NCT03202992). The others are phase III/IV randomized controlled trials evaluating the FDA-approved 9-valent Gardasil
HPV vaccine as a therapeutic strategy, including one for preventing HSIL in women coinfected with HIV and high-risk HPV (COVENANT), and the other for preventing recurrence of HSIL after local ablative therapy for a first vulvar or anal HSIL lesion. 


\section{Interventional Screening Practices and Topical Therapies}

We found 7 trials evaluating screening and treatment practices, all of which are aimed at detecting or treating HPV-associated squamous cell tumors or precursor lesions of cervical, oropharyngeal, or anal cancer (Table 4). One diagnostic trial in the cervix is evaluating the use of HPV screening plus either cytology or visual inspection with acetic acid for the detection of HSIL (NCT03324009). The second diagnostic test pairs carbon monoxide testing with a visual inspection of the oral cavity for malignancies and premalignancies and incorporates smoking cessation with patient follow-up (NCT02823847).

Of the remaining trials, 1 is evaluating the efficacy of topical curcumin in cervical HSIL (NCT02944578), and 4 are focusing on topical or ablative treatments of early invasive anal cancer or HSIL (Table 4). There is no standard of care for treating anal dysplasia, although electrocautery or argon plasma coagulation are both common firstline treatments, and previously documented recur- rence rates have ranged from $0 \%$ to $79 \%$. AMCA01 (ANCHOR; NCT02135419) is investigating whether multimodal treatment of HSIL reduces incidence of anal carcinoma compared with observation in PLWH. AMC-092 (NCT02437851) is evaluating the efficacy of surgical excisional treatment alone for superficially invasive squamous cell carcinoma, and AMC-088 (NCT02059499) is an ongoing randomized study of intra-anal imiquimod $2.5 \%$ versus topical 5-FU 5\% versus observation for the treatment of anal HSIL in PLWH. Finally, a phase II study is evaluating the safety and efficacy of radiofrequency ablation for anal HSIL (NCT03302858).

\section{Future Directions}

There are a broad range of active and soon-to-be-activated trials for HIVAM. Increasingly, as is the case for oncology clinical trials in general, the focus is on immunotherapy and targeted therapy, with lesser emphasis on cytotoxic therapy alone. Although the resulting science from the trials discussed provide

\section{Table 4. Interventional Screening Practices and Topical Therapy for HIV-Associated Malignancy}

\begin{tabular}{|c|c|c|c|}
\hline $\begin{array}{l}\text { Clinical Trial Title } \\
\text { (ClinicalTrials.gov Identifier) }\end{array}$ & Study Interventions & Trial Design ${ }^{\mathrm{a}}$ and Mechanisms & Diseases \\
\hline $\begin{array}{l}\text { Non-Invasive Oral Cancer Screening Among Individuals } \\
\text { Who Have HIV Infection (NCT02823847) } \\
\text { Location: United States } \\
\text { Sponsor: The University of Texas MD Anderson }\end{array}$ & $\begin{array}{l}\text { Procedures: Visual and direct fluorescent } \\
\text { oral screening examination, oral biopsy } \\
\text { Device: Carbon monoxide test }\end{array}$ & $\begin{array}{l}\text { Diagnostic: Evaluate positive predictive } \\
\text { value of these procedures to detect } \\
\text { premalignant and malignant oral } \\
\text { lesions in HIV-infected smokers; ART not } \\
\text { specified }\end{array}$ & $\begin{array}{l}\text { Malignant neoplasms } \\
\text { of mesothelial and } \\
\text { soft tissue }\end{array}$ \\
\hline $\begin{array}{l}\text { Development of a Two-Stage Cervical Cancer Screening } \\
\text { Algorithm for Botswana (NCT03324009) } \\
\text { Location: Botswana } \\
\text { Sponsor: Beth Israel Deaconess Medical Center }\end{array}$ & $\begin{array}{l}\text { Procedures: HPV screen followed by } \\
\text { either Papanicolaou test or VIA }\end{array}$ & $\begin{array}{l}\text { Diagnostic: Determine receiver } \\
\text { operating characteristics for either } \\
\text { HPV/Papanicolaou test or HPV/VIA } \\
\text { algorithms; ART not specified }\end{array}$ & $\begin{array}{l}\text { Women with HIVIAIDS } \\
\text { at risk for cervical } \\
\text { cancer }\end{array}$ \\
\hline $\begin{array}{l}\text { Biomolecular Effects of Topical Curcumin in HSIL Cervical } \\
\text { Neoplasia (NCT02944578) } \\
\text { Location: United States } \\
\text { Sponsor: Emory University }\end{array}$ & $\begin{array}{l}\text { Drug: Intravaginal administration of } \\
\text { topical curcumin }\end{array}$ & $\begin{array}{l}\text { Randomized phase II: Curcumin vs } \\
\text { placebo prior to loop electrosurgical } \\
\text { excision procedure in } \mathrm{HIV+/-}\end{array}$ & Cervical neoplasia \\
\hline $\begin{array}{l}\text { AMC-A01: ANCHOR Study: Anal Cancer/HSIL Outcomes } \\
\text { Research Study (NCT02135419) } \\
\text { Location: United States (including Puerto Rico) } \\
\text { Sponsor: AMC }\end{array}$ & $\begin{array}{l}\text { Drugs: Imiquimod, fluorouracil } \\
\text { Devices: Laser therapy, infrared } \\
\text { photocoagulation therapy, thermal } \\
\text { ablation therapy }\end{array}$ & $\begin{array}{l}\text { Phase III: Compare topical or ablative } \\
\text { treatment vs active monitoring in } \\
\text { preventing anal cancer in patients with } \\
\text { HSIL; ART not specified }\end{array}$ & Anal HSIL \\
\hline $\begin{array}{l}\text { AMC-092: A Multicenter Observational and Feasibility } \\
\text { Study of Excision of Superficially Invasive Squamous Cell } \\
\text { Carcinoma (SISCCA) of the Anal Canal and Perianus in } \\
\text { HIV-Infected Persons (NCT02437851) } \\
\text { Location: United States } \\
\text { Sponsor: AMC }\end{array}$ & $\begin{array}{l}\text { Observational: Following therapeutic } \\
\text { conventional local surgery }\end{array}$ & $\begin{array}{l}\text { Phase II: Persons who have had complete } \\
\text { local excision of superficially invasive } \\
\text { squamous cell cancer followed for } 3 \\
\text { years for recurrence, survival, risk of } \\
\text { colostomy, toxicities; CD4 }>350 \text { cells } / \mathrm{mm}^{3} \\
\text { or on ART }\end{array}$ & $\begin{array}{l}\text { Stage } 0-I \text { anal } \\
\text { squamous cell cancer }\end{array}$ \\
\hline $\begin{array}{l}\text { AMC-088: A Randomized, Phase III Study of Intra- } \\
\text { Anal Imiquimod 2.5\% vs. Topical 5-Fluorouracil 5\% } \\
\text { vs. Observation for the Treatment of High-Grade Anal } \\
\text { Squamous Intraepithelial Lesions in HIV-Infected Men and } \\
\text { Women (NCT02059499) } \\
\text { Location: United States (including Puerto Rico) } \\
\text { Sponsor: AMC }\end{array}$ & Drugs: Imiquimod, fluorouracil & $\begin{array}{l}\text { Phase III, randomized: Efficacy of (1) } \\
\text { intra-anal imiquimod } 2.5 \% \text { and ( } 2 \text { ) intra- } \\
\text { anal topical } 5 \text {-fluorouracil (fluorouracil) } \\
5 \% \text { for treatment of anal HSIL vs } \\
\text { observation alone for both medications; } \\
\text { CD4 }>200 \text { cells } / \mathrm{mm}^{3} \text { and/or virologic } \\
\text { control }\end{array}$ & $\begin{array}{l}\text { Anal intraepithelial } \\
\text { neoplasia, HSIL }\end{array}$ \\
\hline $\begin{array}{l}\text { A Safety and Efficacy Trial of Circumferential Anal } \\
\text { Canal Radiofrequency Ablation for High-Grade Anal } \\
\text { Intraepithelial Neoplasia Using the BARRX Anorectal } \\
\text { Wand (NCT03302858) } \\
\text { Location: United States } \\
\text { Sponsor: Stephen E. Goldstone }\end{array}$ & Device: BARRX anorectal wand & $\begin{array}{l}\text { Phase II: Safety, effectiveness of } \\
\text { circumferential radiofrequency ablation } \\
\text { to the anal canal using the BARRX } \\
\text { ablation system to destroy anal HSIL in } \\
\text { HIV+/- }\end{array}$ & $\begin{array}{l}\text { HSIL } \\
\text { HPV-related squamous } \\
\text { cell carcinoma }\end{array}$ \\
\hline
\end{tabular}

Abbreviations: ART, antiretroviral therapy; HPV, human papillomavirus; HSIL, high-grade squamous intraepithelial lesion; VIA, visual inspection with acetic acid. a Unless otherwise noted, studies include only persons with treated HIV infection (ie, on ART and/or virologic control). 
important translational breakthroughs for PLWH, the following disease-specific challenges need to be addressed in future studies.

\section{Kaposi Sarcoma}

Ongoing challenges in KS include suboptimal efficacy and attendant toxicities of cytotoxic chemotherapy, especially regions that bear the burden of this disease, such as SSA. Given the benefit of ICIs on reversing immune exhaustion, one of the key hypotheses being addressed is that these agents may have synergistic benefit for both HIV and herpesvirus infections, in contrast to other modalities that risk worsening virologic control. However, in addition to the risk of severe immunologic reactions, ${ }^{24}$ cost and requirement for intravenous administration provide barriers to use of these therapies in lowresource settings. Additionally, given lower-thanexpected efficacy of targeted therapies, future KS trials could consider combining multiple, ideally orally available agents with different mechanisms to target redundant KSHV and tumor-promoted angiogenesis and cell survival pathways. ${ }^{25-27}$

\section{HPV-Related Malignancies}

Limited prospective outcome studies are available in HIV-associated cervical cancer, and retrospective studies have demonstrated that PLWH have decreased tolerability to chemoradiotherapy (chemoRT) compared with persons without HIV..$^{28,29}$ Hematologic toxicity, particularly, often results in dose reductions or elimination of concurrent chemotherapy during RT. Future planned studies will examine the toxicities of outback carboplatin/taxol in ART-treated PLWH for 4 cycles after standard chemoRT for locally advanced cervical cancer. In addition, nelfinavir inhibits the phospho-AKT pathway and decreases oxygen consumption. ${ }^{30-32}$ As such, it has been investigated as a radiation sensitizer in a variety of cancers in HIV-negative patients. Compared with common radiation sensitizers, such as platins, potential benefits of nelfinavir include oral administration, relatively manageable side effects, and ease of delivery without refrigeration or handling precautions in low-resource regions.

\section{Lymphoma}

There are many new horizons, including gene therapy, for treatment of lymphoma in higher-resource settings. Most of these could and should include PLWH routinely, and may simultaneously be able to evaluate strategies for HIV cure concurrent with need for cancer treatments. However, with the burden of AIDS-related lymphoma in SSA, and no current standard-of-care in this setting, future trials should focus on moving care toward accepted standards for resourced settings, where HIV infection may no longer be an independent predictor or death, once risk score and receipt of rituximab are taken into account. ${ }^{33}$ Establishing the safety of rituximab in PLWH has been important, as will be ensuring access to this drug, including in the United States, where it is less commonly offered to PLWH. ${ }^{34}$

\section{NADCs and General Considerations}

Most ongoing trials focus on cancers and precancers that are virally mediated and have a higher incidence among PLWH. Only a few phase I studies are investigating appropriate dosing and tolerability of agents among PLWH for NADC, such as anal, lung, hepatocellular, and oropharynx cancers. Future trials will need to determine the dosing and safety of novel cancer therapies for PLWH, as new therapies for cancers that are common in HIV-negative persons begin to be used to treat HIVAMs. This is of particular importance, given that PLWH have been shown to be less likely to receive cancer therapy ${ }^{34}$ and to have poorer outcomes. ${ }^{35}$

Additionally, increasing evidence shows that a robust immune system is critical to cancer control, as evidenced by improved outcomes with immunotherapy for multiple disease sites. ${ }^{36-39}$ Further work identifying and exploiting immunologic and molecular characteristics of cancers in PLWH may also improve treatment outcomes for PLWH.

\section{Summary}

Recently completed trials overall support the position by the Friends of Cancer Research HIV Working Group that, barring specific concerns, PLWH should be treated similar to individuals without HIV infection and should be included in similar trials and standard of care, assuming ART is carefully managed..$^{40}$ However, more research is needed to address several themes in HIVAM. Future trials should focus on not only testing safety and efficacy of cutting-edge immunotherapy and targeted treat- 
Bender Ignacio et al

ments being used in the general cancer population, but also improving the gaps in knowledge and practice for cancer screening and treatment, especially in low-resource regions. Additional important considerations include identifying novel therapies for virally mediated tumors that disproportionally pres- ent in PLWH, treating persons with HIVAM and advanced immunosuppression, and optimizing comanagement of both diseases in ART-naïve persons and those receiving care in settings where supportive therapies for hematologic toxicities and infections are limited..$^{40}$

\section{References}

1. Vandenhende MA, Roussillon C, Henard S, et al. Cancer-related causes of death among HIV-infected patients in France in 2010: evolution since 2000. PLoS One 2015;10:e0129550.

2. Uldrick TS, Ison G, Rudek MA, et al. Modernizing clinical trial eligibility criteria: recommendations of the American Society of Clinical Oncology-Friends of Cancer Research HIV Working Group. J Clin Oncol 2017;35:3774-3780.

3. World Health Organization. Guideline on When to Start Antiretroviral Therapy and on Pre-Exposure Prophylaxis for HIV. Geneva, Switzerland; World Health Organization; 2015.

4. Lundgren JD, Babiker AG, Gordin F, et al. Initiation of antiretroviral therapy in early asymptomatic HIV infection. N Engl J Med 2015;373:795-807.

5. TEMPRANO ANRS 12136 Study Group, Danel C, Moh R, et al. A trial of early antiretrovirals and isoniazid preventive therapy in Africa. N Engl J Med 2015;373:808-822.

6. Vali B, Jones RB, Sakhdari A, et al. HCV-specific T cells in HCV/HIV coinfection show elevated frequencies of dual Tim-3/PD-1 expression that correlate with liver disease progression. Eur J Immunol 2010;40:2493-2505.

7. Moir S, Fauci AS. B-cell exhaustion in HIV infection: the role of immune activation. Curr Opin HIV AIDS 2014;9:472-477.

8. Yanik EL, Napravnik S, Cole SR, et al. Relationship of immunologic response to antiretroviral therapy with non-AIDS defining cancer incidence. AIDS 2014;28:979-987.

9. Jones RB, Ndhlovu LC, Barbour JD, et al. Tim-3 expression defines a novel population of dysfunctional $\mathrm{T}$ cells with highly elevated frequencies in progressive HIV-1 infection. J Exp Med 2008;205:2763-2779.

10. Polizzotto MN, Uldrick TS, Wyvill KM, et al. Pomalidomide for symptomatic Kaposi's sarcoma in people with and without HIV infection: a phase I/II study. J Clin Oncol 2016;34:4125-4131.

11. Trautmann L, Janbazian L, Chomont N, et al. Upregulation of PD-1 expression on HIV-specific CD8+ T cells leads to reversible immune dysfunction. Nat Med 2006;12:1198-1202.

12. Kaufmann DE, Kavanagh DG, Pereyra F, et al. Upregulation of CTLA-4 by HIV-specific CD4+ T cells correlates with disease progression and defines a reversible immune dysfunction. Nat Immunol 2007;8:1246-1254.

13. Zaunders JJ, Ip S, Munier ML, et al. Infection of CD127+ (interleukin-7 receptor+) CD4+ cells and overexpression of CTLA-4 are linked to loss of antigen-specific CD4 T cells during primary human immunodeficiency virus type 1 infection. J Virol 2006;80:10162-10172.

14. Velu V, Titanji K, Zhu B, et al. Enhancing SIV-specific immunity in vivo by PD-1 blockade. Nature 2009;458:206-210.

15. Ambinder RF, Wu J, Logan B, et al. Allogeneic hematopoietic cell transplant (alloHCT) for hematologic malignancies in human immunodeficiency virus infected (HIV) patients (pts): Blood and Marrow Transplant Clinical Trials Network (BMT CTN 0903)/AIDS Malignancy Consortium (AMC-080) trial [abstract]. J Clin Oncol 2017;35(15 Suppl):Abstract 7006.

16. Podsakoff GM, Engel BC, Carbonaro DA, et al. Selective survival of peripheral blood lymphocytes in children with HIV-1 following delivery of an anti-HIV gene to bone marrow CD34(+) cells. Mol Ther 2005;12:77-86.

17. Rubinstein PG, Moore PC, Rudek MA, et al. Brentuximab vedotin with AVD shows safety, in the absence of strong CYP3A4 inhibitors, in newly diagnosed HIV-associated Hodgkin lymphoma. AIDS 2018;32:605-611.

18. Skitzki JJ, Repasky EA, Evans SS. Hyperthermia as an immunotherapy strategy for cancer. Curr Opin Investig Drugs 2009;10:550-558.

19. Andocs G, Rehman MU, Zhao QL, et al. Comparison of biological effects of modulated electro-hyperthermia and conventional heat treatment in human lymphoma U937 cells. Cell Death Discov 2016;2:16039.

20. Pang CLK, Zhang $X$, Wang Z, et al. Local modulated electro-hyperthermia in combination with traditional Chinese medicine vs. intraperitoneal chemoinfusion for the treatment of peritoneal carcinomatosis with malignant ascites: a phase II randomized trial. Mol Clin Oncol 2017;6:723-732.
21. Gantt S, Carlsson J, Ikoma M, et al. The HIV protease inhibitor nelfinavir inhibits Kaposi's sarcoma-associated herpesvirus replication in vitro. Antimicrob Agents Chemother 2011;55:2696-2703.

22. Gantt $S$, Casper $C$, Ambinder RF. Insights into the broad cellular effects of nelfinavir and the HIV protease inhibitors supporting their role in cancer treatment and prevention. Current Opin Oncol 2013;25:495-502.

23. Gantt S, Cattamanchi A, Krantz E, et al. Reduced human herpesvirus- 8 oropharyngeal shedding associated with protease inhibitor-based antiretroviral therapy. J Clin Virol 2014;60:127-132.

24. Postow MA, Hellmann MD. Adverse events associated with immune checkpoint blockade. N Engl J Med 2018;378:1165.

25. Rudek MA, Moore PC, Mitsuyasu RT, et al. A phase $1 /$ pharmacokinetic study of sunitinib in combination with highly active antiretroviral therapy in human immunodeficiency virus-positive patients with cancer: AIDS Malignancy Consortium trial AMC 061. Cancer 2014;120:1194-1202.

26. Bender Ignacio RA, Lee JY, Rudek MA, et al. A phase $1 \mathrm{~b} /$ pharmacokinetic trial of PTC299, a novel post-transcriptional VEGF inhibitor, for AIDS related Kaposi's sarcoma: AIDS Malignancy Consortium trial 059. J Acquir Immune Defic Syndr 2016;72:52-57.

27. Uldrick TS, Wyvill K, Peer C, et al. Phase I and pharmacokinetic study of sorafenib in Kaposi sarcoma [abstract]. J Clin Oncol 203;31(Suppl):Abstract 10588 .

28. Simonds HM, Wright JD, du Toit N, et al. Completion of and early response to chemoradiation among human immunodeficiency virus (HIV)-positive and HIV-negative patients with locally advanced cervical carcinoma in South Africa. Cancer 2012;118:2971-2979.

29. Ferreira MP, Coghill AE, Chaves CB, et al. Outcomes of cervical cancer among HIV-infected and HIV-uninfected women treated at the Brazilian National Institute of Cancer. AIDS 2017;31:523-531.

30. Gupta AK, Li B, Cerniglia GJ, et al. The HIV protease inhibitor nelfinavir downregulates Akt phosphorylation by inhibiting proteasomal activity and inducing the unfolded protein response. Neoplasia 2007;9:271-278.

31. Pore N, Gupta AK, Cerniglia GJ, et al. Nelfinavir down-regulates hypoxiainducible factor 1alpha and VEGF expression and increases tumo oxygenation: implications for radiotherapy. Cancer Res 2006;66:9252-9259.

32. Lin A, Maity A. Molecular pathways: a novel approach to targeting hypoxia and improving radiotherapy efficacy via reduction in oxygen demand. Clin Cancer Res 2015;21:1995-2000

33. Cingolani A, Cozzi Lepri A, Teofili L, et al. Survival and predictors of death in people with HIV-associated lymphoma compared to those with a diagnosi of lymphoma in general population. PLoS One 2017;12:e0186549.

34. Rositch AF, Jiang $\mathrm{S}$, Coghill $\mathrm{AE}$, et al. Disparities and determinants of cancer treatment in elderly Americans living with HIV/AIDS [published online ahead of print]. Clin Infect Dis, doi: 10.1093/cid/ciy373

35. Suneja G, Shiels MS, Melville SK, et al. Disparities in the treatment and outcomes of lung cancer among HIV-infected individuals. AIDS 2013;27:459-468.

36. Antonia SJ, Villegas A, Daniel D, et al. Durvalumab after chemoradiotherapy in stage III non-small-cell lung cancer. N Engl J Med 2017;377:1919-1929.

37. Eggermont AM, Blank CU, Mandala M, et al. Adjuvant pembrolizumab versus placebo in resected stage III melanoma. N Engl J Med 2018;378:17891801 .

38. Gandhi L, Rodriguez-Abreu D, Gadgeel S, et al. Pembrolizumab plus chemotherapy in metastatic non-small-cell lung cancer. N Engl J Med 2018;378:2078-2092.

39. Nghiem PT, Bhatia S, Lipson EJ, et al. PD-1 Blockade with pembrolizumab in advanced Merkel-cell carcinoma. N Engl J Med 2016;374:2542-2552.

40. Alvarnas JC, Zaia JA, Forman SJ. How I treat patients with HIV-related hematological malignancies using hematopoietic cell transplantation. Blood 2017;130:1976-1984 